\title{
REFRACTIVE ERROR STATUS IN BAYELSA STATE, NIGERIA
}

\author{
BY \\ KOROYE-EGBE, A., *OVENSERI-OGBOMO, G. O. AND ADIO, A. O. \\ DEPARTMENT OF OPTOMETRY, UNIVERSITY OF CAPE COAST, GHANA \\ Email: ovenseriogbomo@yahoo.com \\ *Corresponding author
}

\begin{abstract}
Refractive errors affect the whole spectrum of the population without regard to age, gender, race and ethnic group. Uncorrected refractive errors have severe consequences for the individual, family and society. Records show that no study documenting the distribution of refractive errors in Bayelsa State had been carried out. Records of patients who presented between January, 2004 and October, 2005 in the government-subsidized eye clinic of the Niger-Delta University Teaching Hospital, Okolobiri for refractive error service were reviewed. Myopia was defined as $\geq-0.50 \mathrm{DS}$; hyperopia as $\geq+1.00 \mathrm{DS}$ while astigmatism was defined as $\geq-0.25 \mathrm{DC}$. Emmetropia was defined as spherical power of $-0.25 \mathrm{D}$ to $+0.75 \mathrm{D}$. Results of the right eye were used for analysis. Data were analyzed using the Statistical Package for Social Sciences (SPSS) version 10. In this retrospective study, a total of 654 patients fitted the inclusion criteria. There were 319 males and 335 females (48.78\% and 51.22\% respectively) with an age range of 5 - 86 years. Mean age was $42.18 \pm 13.10(95 \% \mathrm{CI}=41.17-43.19)$ years. Significant refractive error was observed in 355 cases $(54.28 \%)$ while $299(45.72 \%)$ were emmetropic. Of the 355 with refractive error, $181(50.99 \%)$ were male and $174(49.01 \%)$ were females. Astigmatism was the commonest refractive error $(n=162,45.63 \%)$ followed by myopia $(n=113,51.83 \%)$ and hyperopia $(n=80,22.54 \%)$. The ranges of refractive power were as follows: astigmatism, $-0.25 \mathrm{DC}$ to $-1.75 \mathrm{DC}$; Myopia, $-0.50 \mathrm{D}$ to $-9.00 \mathrm{D}$ and hyperopia, +1.00DS to +11.00DS. More males had hyperopia and myopia while more females had astigmatism. Presbyopia as indicated by the use of near addition was present in $490(74.92 \%)$ of the subjects. The results can be used for planning self sustaining refractive error services in the state.
\end{abstract}

KEYWORDS: Emmetropia, Myopia, Hyperopia, Astigmatism, Presbyopia.

\section{INTRODUCTION}

In the last few years considerable attention has been drawn to the contribution of refractive errors to global cause of visual impairment and blindness. This resulted from the realization that previous global estimates of blindness and visual impairment have underestimated the contribution of refractive errors. The use of best corrected visual acuity rather that presenting visual acuity has led to this underestimation.

Refractive errors (myopia, hyperopia and astigmatism) affect the whole spectrum of the population without regard to age, gender, race and ethnic group. Uncorrected or under-corrected refractive errors have severe consequences for the individual, family and society. These include lost educational and employment opportunity, as well as economic cost to the family and government. Smith and Smith ${ }^{1}$ have estimated that the annual worldwide productivity cost of blindness is $\$ 168$ billion. Uncorrected refractive error has also been linked with poverty. It has been noted that "without appropriate optical correction, millions of children are losing educational opportunities and adults are excluded from productive working lives, with severe economic and social consequences. Individuals and families are pushed into a cycle of deepening poverty because of their inability to see well" ${ }^{2}$.

In 2002, the estimate of global visual impairment was put at 161 million from all causes besides refractive error ${ }^{3}$. This value rose to 314 million in 2004 when refractive error was included in the estimation ${ }^{4}$. Refractive error alone caused 153 million ( 8 million blind, 145 million low vision) thus making refractive error the leading cause of low vision and the second leading cause of blindness following cataract which remained the leading cause of blindness globally.

Various studies have documented the prevalence of refractive errors in different population groups. Among adult Chinese population in Singapore, the overall prevalence of myopia, hyperopia and astigmatism was $38.7 \%$, 
$28.4 \%$ and $37.8 \%$ respectively. The prevalence of high myopia (>-5.00D) was $9.15 \%{ }^{5}$. The prevalence of myopia in India has been reported to be $29 \%$ in adults 30 years and older ${ }^{6}$ and $22 \%$ in Bangladesh $^{7}$ where refractive error was the second leading cause of visual impairment following cataract. The study also reported the prevalence of hyperopia (>+0.50D) to be $20.6 \%$ in Bangladesh. A recent national survey in Pakistan has reported that refractive error is the commonest cause of moderate visual impairment (VA $<6 / 18$ to $\geq 6 / 60$ ) accounting for $43 \%$ followed by cataract ${ }^{8}$. A hospital-based survey in Central Region, Ghana has shown that refractive error is the cause of $29.2 \%$ of visual impairment second only to cataract ${ }^{9}$. Refractive error is the second leading cause of low vision $(\mathrm{VA}=6 / 24 \quad 6 / 60)$ in Ethiopia accounting for $25.5 \%{ }^{10}$.

Studies in different parts of Nigeria have documented refractive error findings. The results of these studies vary considerably on the distribution of refractive errors in Nigeria. In IleIfe, Osun State, $54.9 \%$ of the patients examined over a 12 months period had refractive error with a preponderance of myopia present in $22.7 \%$ of those with refractive errors ${ }^{11}$ whereas hyperopia was the commonest refractive error in Kaduna $(21.7 \%)^{12}$.

We did not find any study documenting the distribution of refractive error in Bayelsa State. The aim of this study was to determine the distribution of refractive errors in Bayelsa State.

\section{RESEARCH METHODOLOGY}

Records of consecutive patients who visited the eye unit of the Niger-Delta University Teaching Hospital, Okolobiri between January 2004 and October 2005 were retrieved for the study. The hospital is the major public facility providing eye care services for the entire state as at the time of this study. The Eye Clinic is manned by an Ophthalmologist, an Optometrist (who performed all the refractions) and other health workers. During the period covered by this study, refractive error services were paid for by the Bayelsa State Government.

Bayelsa State is in the South-South geopolitical zone of Nigeria. It has an estimated population of 2 million and covers an estimated
$21,100 \mathrm{~km}^{13}$. The major occupations in the State are fishing, farming, palm oil milling, lumbering, palm wine tapping, and local gin making, trading, carving and weaving ${ }^{13}$.

All patients who visited the clinic for refraction were included in the study except in cases where lenses did not improve vision or details of the refractive findings were not recorded. Refractive error included myopia, hyperopia and astigmatism. Myopia was defined as $\geq-0.50 \mathrm{DS}$; hyperopia as $\geq$ $+1.00 \mathrm{DS}$ while astigmatism was defined as $\geq$ $0.25 \mathrm{DC}^{14}$. Emmetropia was defined as spherical power of $0.25 \mathrm{D}$ to $+0.75 \mathrm{D}$. Every patient who needed a reading addition was considered as having presbyopia particularly if there was a history of difficulty in reading fine prints. The results of the right eye were used for analysis and for computing spherical equivalent. The data were analyzed using the Statistical Package for Social Sciences (SPSS) version 10.

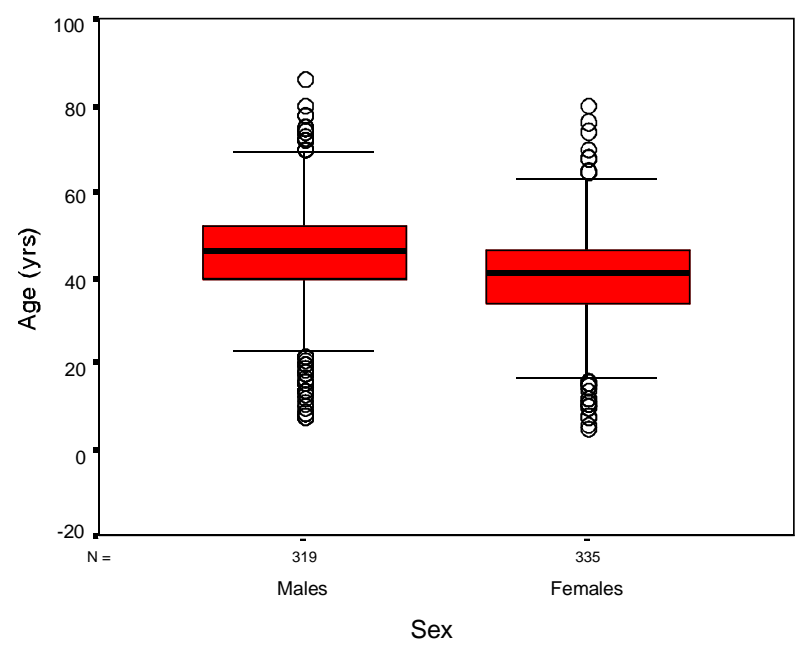

Fig1: Box Plot of the Ages of Males and Females

\section{RESULTS}

A total of 671 case records were retrieved for the study. Using the exclusion criteria indicated above, the records of 654 subjects were reviewed for analysis giving a response rate of $97.47 \%$. This consisted of 319 males and 335 females $(48.78 \%$ and $51.22 \%$ respectively) aged 586 years. The mean age of the subjects was $42.18 \pm 13.10$ (95\% CI $=41.17-43.19)$ years.

The mean ages of males and females were 45.32 (95\% $\mathrm{CI}=43.85-46.78)$ and $39.19(95 \% \mathrm{CI}=$ 37.88-40.51) years respectively. This difference was significant $(p=0.000)$. Fig. 1 shows the box plot for the ages of males and females. Significant 


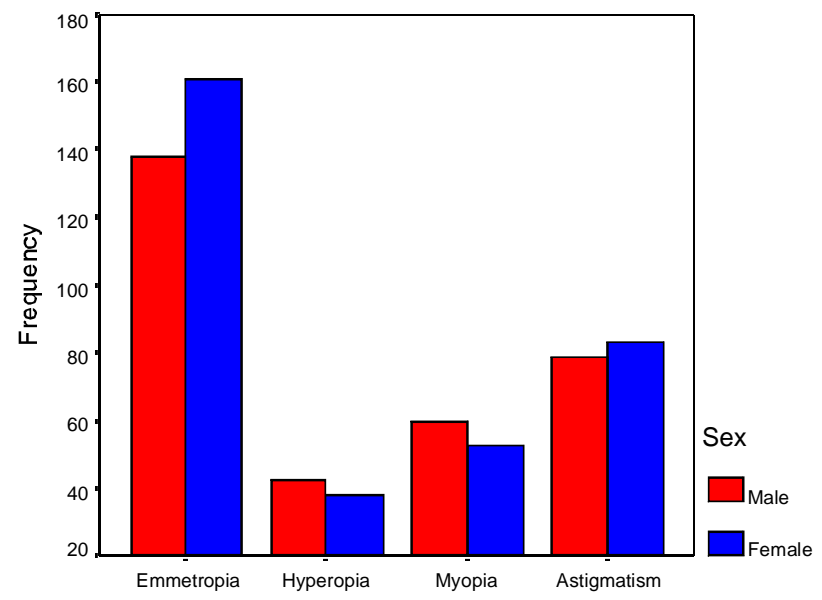

Refractive Error for right eye

Figure 2: Distribution of Refractive Status by Sex

refractive error was observed in $355(54.28 \%)$ while 299 (45.72\%) were emmetropic. Of the 355 with refractive error, $181(50.99 \%)$ were male and $174(49.01 \%)$ were females. The refractive status of the subjects was independent of the gender $\left(^{2}=\right.$ $2.111, p=0.550)$. It was however dependent on the age of the subjects $(\mathrm{p}=0.000)$.

Hyperopia was present in 80 subjects which represented $22.54 \%$ of those with refractive error. Similarly, myopia and astigmatism were present in 113 and 162 subjects representing $31.83 \%$ and $45.63 \%$ of those with refractive error respectively. More males had hyperopia and myopia while more females had astigmatism (fig. 2).

The ranges of refractive powers were as follows: myopia, $-0.50 \mathrm{D}$ to $-9.00 \mathrm{D}$; hyperopia, +1.00DS to +11.00DS; and astigmatism, -0.25DC to $-1.75 D C$. Spherical equivalent was computed using the subjective refraction of the right eye. The mean spherical equivalent (MSE) was -0.17DS $(\mathrm{SD}=1.695,95 \% \mathrm{CI}=-0.304$ to -0.043$)$. The MSE was different for male compared to female though this difference was not significant $(\mathrm{t}=-0.496, \mathrm{p}=$ 0.620). Male MSE was -0.207DS (SD $=1.654$, $95 \% \mathrm{CI}=-0.389$ to -0.0248$)$ and that of female was $-0.1413 \mathrm{DS}(\mathrm{SD}=1.735,95 \% \mathrm{CI}=-0.3277$ to $0.04519)$.

Presbyopia as indicated by the use of near addition was present in $490(74.92 \%)$ of the subjects. Males accounted for $51.80 \%$ of the presbyopia while females were $48.20 \%$. The mean reading addition was $1.9546(\mathrm{SD}=0.5160,95 \% \mathrm{CI}$ $=1.90882 .0004)$. The reading addition prescribed ranged from $+1.00 \mathrm{D}$ to $+5.00 \mathrm{D}$. The majority of reading additions were between $+1.50 \mathrm{D}$ to $+2.50 \mathrm{D}$ which accounted for $82.90 \%$ of the total addition prescribed. Fig. 3 shows the histogram of the distribution of reading additions.

The independent t-test for difference of mean showed that the mean reading addition was significantly different for both males and females $(\mathrm{t}$ $=3.580, \mathrm{p}=0.000)$. The mean reading addition for males was $+2.0335 \mathrm{D}(\mathrm{SD}=0.56,95 \% \mathrm{CI}=1.9643$ $2.1027)$ and females was $+1.8697 \mathrm{D}(\mathrm{SD}=0.4499$, $95 \% \mathrm{CI}=1.8121 .9274$ ).

The minimum age at which a subject was prescribed with a reading addition was 30years. The mean presbyopic age was $46.58 \pm 8.12$ years. The Pearson correlation coefficient showed that there was a positive correlation between age and reading addition $(\mathrm{r}=0.654, \mathrm{p}=0.000)$. The scatter plot shows the relationship between reading addition and age (fig. 4).

\section{DISCUSSION}

To the best of our knowledge, there is no documentary evidence describing the refractive error status in Bayelsa state. This report will therefore provide preliminary report of the refractive error status in Bayelsa State.

Being hospital based, the study has the inherent limitation of hospital based studies. These include, but not limited to, selection bias, poor recording system and inconsistent data sources. The selection bias results from the fact that only those with a subjective awareness of the visual problem will present for examination. Secondly, the figure may be bloated due to the free eye care services provided by the government including free spectacles whenever prescribed. Poor record keeping and filing system is a present concern in health facilities in developing countries. Notwithstanding the aforementioned limitations, the results of the present study can be used for planning refractive error services and evaluating the government's free eye care services.

Our results indicated that refractive error was present in 54.28\%. This figure appears high compared to other studies in Ghana ${ }^{9}$, and Ethiopia ${ }^{10}$ but consistent with studies from Pakistan ${ }^{8}$. It is also consistent with a clinic based study in IleIfe ${ }^{11}$. A recent hospital based study in Ghana showed that refractive error was present in $44.3 \%$ of the subjects studied ${ }^{15}$. A community based study in 
Rivers State one of the neighbouring states to Bayelsa state, however showed that up to $32.1 \%$ of the population had low vision resulting from uncorrected refractive errors if presbyopia is excluded $^{16}$. These differences may largely be accounted for by the varied criteria for defining the various types of refractive error observed in different studies. This may also be responsible for the variation in the preponderance of the types of refractive errors. The World Health Organization (WHO) and the International Agency for the Prevention of Blindness (IAPB), both separately and in their joint initiative, VISION 2020: The Right to Sight, have been working very hard to put uncorrected refractive error on the blindness prevention agenda and to develop strategies for the elimination of this most simple avoidable cause of vision $\operatorname{loss}^{17}$. In this study astigmatism was the commonest refractive error followed by myopia and then hyperopia. In Kaduna, hyperopia was the commonest spherical ametropia, present in $21.7 \%$ of the subjects though in that study hyperopia was defined as $\geq+0.25 \mathrm{D}^{12}$.

The magnitude of severe near visual impairment due largely to presbyopia has not been well documented ${ }^{17}$. Our study showed that $74.92 \%$ of the subjects had presbyopia. This figures is high compared to $31.8 \%$ reported for southwest Nigeria $^{11}$ and $56 \%$ for northern Nigeria ${ }^{12}$. A comparison of the age of presentation for presbyopia shows that Bayelsa is lower (30 years) compared to Ile-Ife (36 years). This may not be unrelated to the fact that there is a free eye care service in place in Bayelsa State where spectacle lenses are provided at no cost to the patients. The majority of additions prescribed ranged between $+1.50 \mathrm{D}$ to $+2.50 \mathrm{D}$. This is instructive from the point of view of planning for refractive error services. Stocking reading lenses in this range can serve the need of about $83 \%$ of the presbyopic population.

Our study has shown that refractive error is a common finding and cause of presentation to the eye clinic in Bayelsa state. It has become essential to plan and find the solution to uncorrected refractive error. The free eye care program may have contributed to the uptake of refractive error services in the State.

The review of the case records of the patients attending the refraction clinic of the Niger Delta University Teaching Hospital, Okolobiri, Bayelsa State has shown the pattern of the refractive error within the general population of the area. Every effort must be made to meet the goals of VISION 2020 and eliminate uncorrected refractive error within the next few years. This will save the community a lot of money when those needlessly blind or visually impaired do not have to depend on others to exist. With this information, a plan for setting up a self sustaining and low cost lens dispensing service can be made which had been nonexistent at the time of writing this paper.

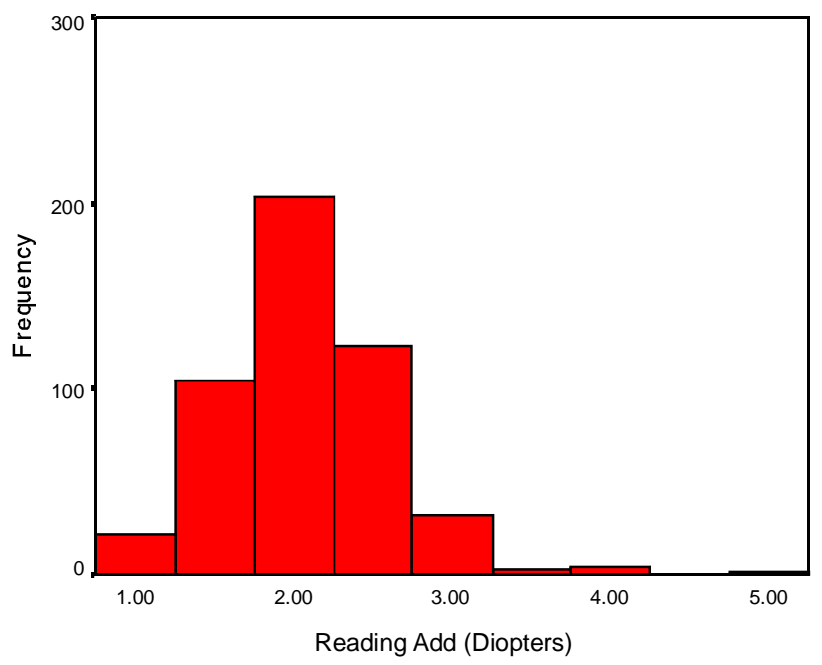

Figure 3: Histogram showing the distribution of reading additions

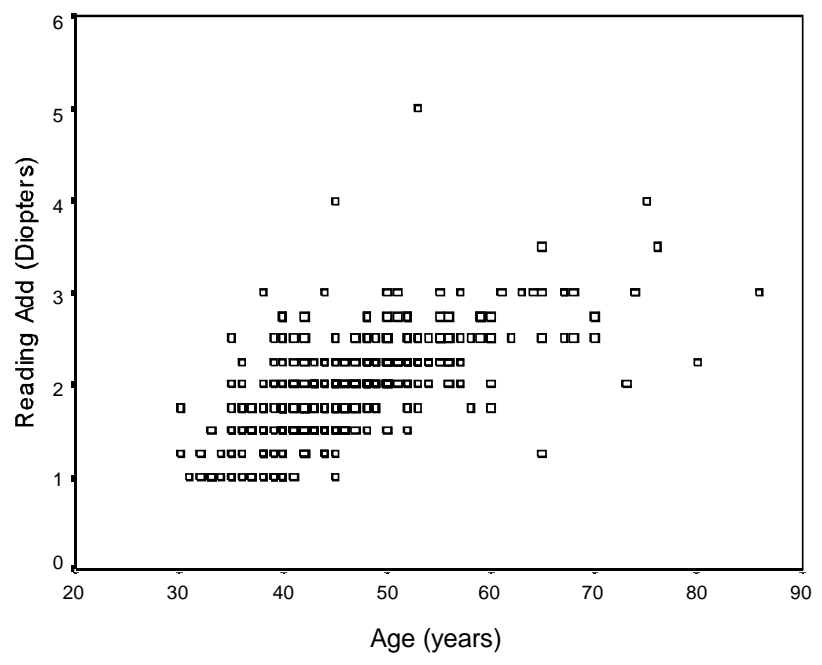

Figure 4: Scatter plot of reading addition against age 


\section{REFERE NCE S}

1. Smith, A. F. and Smith, J. G. (1996): The economic burden of global blindness: a price too high! Br. J. Ophthalmol, 80(4):276 -7.

2. WHO press release. Sight test and glasses could dramatically improve the lives of 150 million people with poor vision. Geneva. October 11, 2006.

3. Resnikoff, S., Pascolini, D., Etya'ale, D., Kocur, I., Pararajasegaram, R. and Pokharel, G. P. (2004): Global data on visual impairment in the year 2002. Bull. WHO, 82(11):844-51.

4. Resnikoff, S., Pascolini, D., Mariotti, S. P. and Pokharel, G. P. (2008): Global magnitude of visual impairment caused by uncorrected refractive errors in 2004. Bull. WHO, 86(1):63-70.

5. Wong, T. Y., Foster, P. J., Hee, J., Ng, T. P., Tielsch, J. M. and Chew, S. J. (2000): Prevalence and risk factors for refractive errors in adult Chinese in Singapore. Invest. Ophthalmol. Vis. Sci, 41(9):248694.

6. Dandona, R., Dandona, L., Srinivas, M., Giridhar, P., McCarty, C. and Rao, G. N. (2002): Population-based assessment of refractive error in India: the Andhra Pradesh eye disease study. Clin. Expt. Ophthalmol, 30(2):8493.

7. Bourne, R. R. A., Dineen, B. P., Modasser, A. S., Mohammed, N. H. D. and Johnson, G. J. (2004): Prevalence of refractive error in Bangladeshi adults: results of the National Blindness and Low Vision Survey of Bangladesh. Ophthalmol, 111(6): 1150-60.

8. Dineen, B., Bourne, R. R., Jadoon, Z., Shah, S. P., Khan, M. A. and Foster, A. (2007): Causes of blindness and visual impairment in
Pakistan. The Pakistan National Blindness and Visual impairment survey. Br. J. Ophthalmol, 91(8):1005-10.

9. Ovenseri-Ogbomo, G. and Morny, E. K. (2008): Causes of visual impairment in Central Region, Ghana. JNOA, 14:11-13.

10. Melese, M., Alemayehu, W., Bayu, S., Girma, T., Haillesellasie, T. and Khandekhar, R. (2003): Low vision and blindness in adults in Gurage Zone, central Ethiopia. Br. J. Ophthalmol, 87(6):677-80.

11. Adegbehingbe, B. O., Majekodunmi, A. A., Akinsola, F. B. and Soetan, E. O. (2003): Pattern of refractive errors at Obafemi Awolowo University Teaching Hospital, IleIfe, Nigeria. Nig. J. Ophthalmol, 11:76-9.

12. Bagaiya, T. and Pam, V. (2003): Refractive errors in Kaduna, Nigeria. Nig. J. Surg. Res, 5:106-9.

13. Bayelsa State Union, Bayelsa State.

14. Mabaso, R. G., Oduntan, A. O. and Mpolokeng, M. B. L. (2006): Refractive error status of Primary School Children in Mopani District, Limpopo Province, South Africa. S. Afr. Optom. J, 65(4):125-33.

15. Ntim-Amponsah, C. T. (2007): Contribution of refractive errors to visual impairment in patients at Korle-Bu Teaching Hospital. Ghana Med. J, 41(2):68 71.

16. Omoni, A. O. (2005): The epidemiology of blindness and visual impairment in a fishing village in Nigeria. TNHJ, 15(1-2):252-60.

Holden, B. A. (2007): Uncorrected refractive error: the major and most easily avoidable cause of vision loss (editorial). Comm. Eye Hlth, 20(63):37-9. 